\title{
A NEW DECISION SUPPORT SYSTEM FRAMEWORK FOR BALANCED SCORECARD AND ITS APPLICATON IN A LOGISTICS COMPANY
}

*Ufuk CEBECI

*Istanbul Technical University, Turkey

\begin{abstract}
The aim of this study is to develop a new decision support framework for balanced scorecard and to apply it to balanced scorecard's each stage. The literature studies reveal that there is an obvious lack of studies that focus on integrated approach for balanced scorecard stages. Therefore, an integrated approach is proposed from vision to action as a whole. The approach including 10 stages is developed originally. The new decision support system framework helps managers to design balanced scorecard effectively. The paper finds that an integrated approach should be applied for the implementation of balanced scorecard. Also, expert knowledge is required for every stage of balanced scorecard to support managers. The model gives recommendations for every stage of balanced scorecard and it is applied to a global Turkish logistics company successfully, and the results are satisfactory. The proposed new framework is formed by using some experts' opinion about balanced scorecard, and logistics. Some firms, software houses and experts are visited to obtain necessary information and knowledge.
\end{abstract}

Key Words: Balanced Scorecard, Decision Support Systems, Strategic Management, Logistics.

\section{INTRODUCTION}

The Balanced Scorecard (BSC) is one of the most common applications of performance management in all types of organizations (private sector, non-profit organizations, and government) all over the world. It is used to increase the performance of a company and the performance of employees by starting from vision, strategies and other long term concepts. BSC enables management to execute their strategies. ERP systems focus on integrating different business functions and departments in an efficient manner, while BSC uses the information derived from Enterprise Resource Planning (ERP) systems to focus the strategies, goals, objectives, and performance. The balanced scorecard is a tool that can help translating visions and strategies into an integrated set of performances and actions. Kaplan and Norton (1992) introduced the balanced scorecard concept as a strategic performance management system. A strategic planning study such as balanced scorecard is very useful from vision to action. Kaplan and Norton (1996) state that "the balanced scorecard translates an organization's mission, vision and strategy into a comprehensive set of performance measures and provides the framework for strategic measurement and management". The balanced scorecard concept measures organizational performance across four balanced perspectives: financial perspective, customer perspective, internal business perspective, and learning and growth perspective. These perspectives state that balanced scorecard tells you the knowledge, skills and systems that your employees will need (learning and growth perspective) to innovate and build the right strategic capabilities and efficiencies (internal processes perspective) that deliver specific value to the market (customer perspective) which will eventually lead to higher shareholder value (financial perspective). (Figure 1)

The literature studies reveal that there is an obvious lack of scientific studies that focus on integrated approach for balanced scorecard stages. Therefore, an integrated approach is proposed from vision to action as a whole. The approach including 10 stages is developed originally. The new decision support system framework helps managers to design balanced scorecard effectively. And it is applied to a logistics company successfully. 


\section{LITERATURE REVIEW}

Pimentel and Major's study (2014) monitors that organizations can successfully integrate quality management and BSC. It covers a government agency as a case study. Garengo and Biazzo (2012) connected the actual strategy with the intentional strategy and engaged SMEs in a process of observation and clarification of their future vision. A business excellence model is examined from a critical perspective by analyzing the results from a three year university/organization partnership by a TQM

\section{Figure 1 The structure of Balanced Scorecard developed by Kaplan and Norton} (1996)

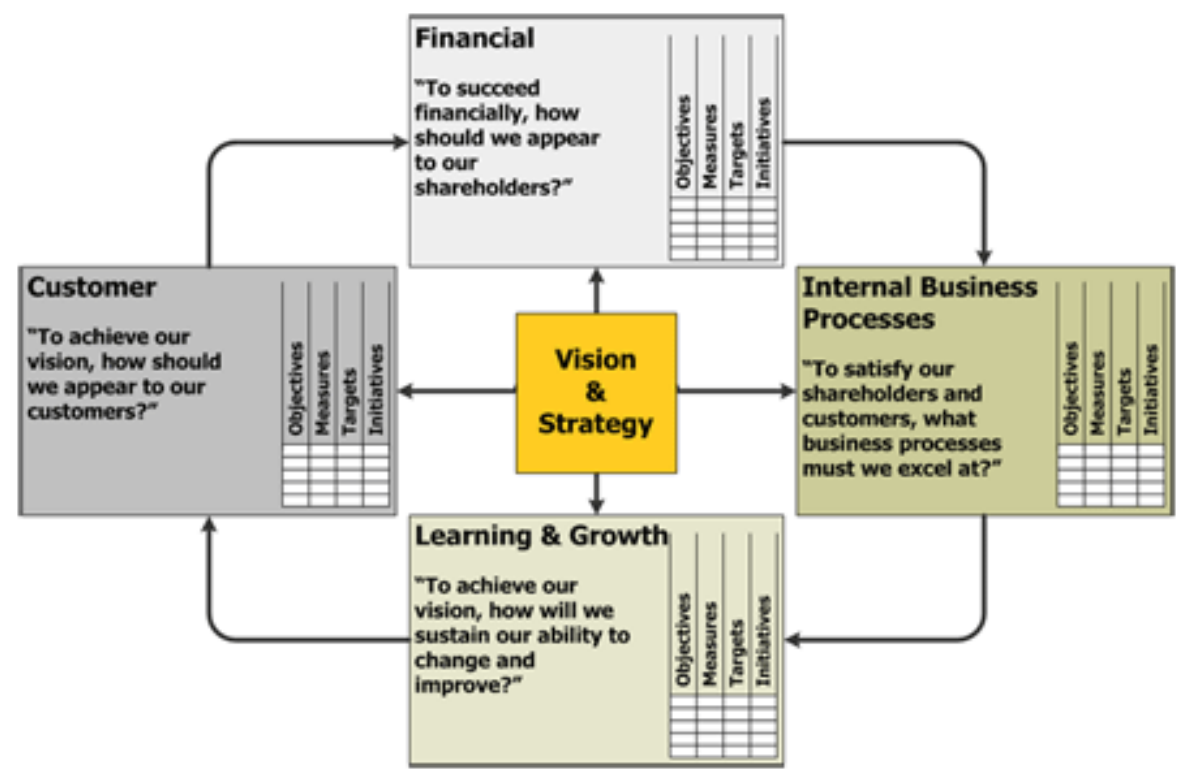

team. A balanced scorecard approach was used to cover deficiencies in the Business Excellence Model (McAdam et al., 1999). Chang et al. (2008) assessed both direct and indirect outcomes of the implementation of Balanced Scorecard in a hospital in Taiwan since its inception in 2001. MMH is the first hospital in Taiwan to implement the Balanced Scorecard fully for the entire organization, not just for a specific department. Asan and Tanyas (2007) combined a performance-oriented approach similar to the Balanced Scorecard with a process-oriented approach like Total Quality Management's Hoshin Kanri to create synergy. Balance scorecard matches the concept of total quality management of continuous improvement. It is a useful tool to evaluate an enterprise's total operation performance (Wu and Hung, 2007). Wu and Hung outline to measure criteria toward each performance perspective of a balance scorecard in cause-related marketing. Singh et al. (2018) proposed a sustainability evaluation method for manufacturing SMEs using balanced scorecard framework. Xia et al. (2017) published a study about sustainable technology selection decision-making model for enterprise in supply chain, based on a balanced scorecard. Cebeci (2009) proposed a fuzzy AHP-based decision support system to select ERP systems by using balanced scorecard and its case study was applied in a textile company. A BSC study needs ERP infrastructure. Esteves (2009) has described the road-map for an effective ERP system integration in SMEs. Federici, (2009) has explained some other factors affecting ERP outcomes of SMEs. Gunasekaran and Kobu (2007) review performance measures and metrics in logistics and supply chain management. They present the classification of literature on performance measures and metrics. Huang (2009) suggests a knowledge-based system for strategic planning including balanced scorecard. RitchieDunham et al. (2007) present a computer-based simulation exercise on business performance in a service supply chain. Rajesh et al. (2012) proposed a set of strategies for BSC of 3PL service providers. A strategic framework for all the four BSC perspectives of the various functions of 3PL service providers are devised and the weightages for the different strategies are evaluated using Delphi analysis.

Kalkan et al. (2015) studied the strategic management approach in the metropolitan municipalities in Turkey. It is important to select, to manage and to balance the right Key Performance Indicators (KPI) among thousands that can be produced by ERP systems for every management level and units. 
Companies define their vision, strategies and goals at top management level, but they cannot apply deployment at medium or lower level management and units. They need expert knowledge to build an effective performance management system and BSC in every stage and they ask a lot of questions such as: How to define a shared vision? How to apply SWOT analysis? Which strategies are important for my sector and my organization? How to apply Balanced Scorecard in logistics industry? How many strategies are necessary for my organization? How to develop strategy? How to link the company-wide strategic objectives and company-wide strategy? Which Key Performance Indicators (KPI) are more important for my organization? What is the formula of every Key Performance Indicator? How many objectives are necessary at company level? How many objectives are necessary at unit level? How many objectives are necessary at unit manager level? How many objectives are necessary at employee level? What are the periods to control Key Performance Indicator? What is the most suitable unit for every Key Performance Indicator? How to calculate alarm value of an objective? What is the percentage (weight) of objective when calculating the performance value of an employee? Should the percentage (weight) of objectives change according to department such as marketing, purchasing, production? All these questions and more need expert knowledge. One of the objectives of this study is to answer these important questions by developing a framework of balanced scorecard decision support system for the companies in logistics sector. Another objective is to help a user who wants to build a balanced scorecard by giving some suggestions and recommendations when analyzing the necessary data derived generally from ERP system of the organization. In general, scientific studies related balanced scorecard focus on some parts of balanced scorecard. However, balanced scorecard concept needs to be implemented from vision to action and at operational level. In this study, an integrated approach is developed from vision to action as a whole.

\section{Decision Support Systems}

Decisions making by managers in firms are critical for their success. Accurate, in time and fast decisions increase the competitiveness of firms. Gorry and Scott Morton used the term "decision support system" firstly (1971). Decision Support Systems (DSS), in general meaning, are computer based information systems that generate and evaluate effective alternatives about decision which is necessary to solve the problem by understanding and using available data. DSS helps to compensate managers' knowledge deficiency. They are mainly used in semi-structured and unstructured situations. Intelligent Decision Support Systems (iDSS) are interactive computer-based systems that use data, expert knowledge and models for supporting DMs in organizations to solve semi structured problems by incorporating artificial intelligence techniques (V. Sarma, 1994.) Expert Systems: Expert systems (ES) are artificial intelligence based systems that convert the knowledge of an expert in a specific subject into a software code. The application of ES in the textile industry can help firms (Metaxiotis, 2004) to decrease setup time by identifying more appropriate activities and devise more efficient and objective planning in their production (Ford, 1995). Knowledge-based Systems: Knowledge-based systems are softwares that uses artificial intelligence or expert system techniques in problem solving processes. The system incorporates a store (database) of expert knowledge with couplings and linkages designed to facilitate its retrieval in response to specific queries, or to transfer expertise from one domain of knowledge to another (Laudon, 2002). In a textile company, KBS can diagnose manufacturing problems (Hussain, 2005).

\section{The Developed Balanced Scorecard Decision Support System (BS-DSS) for Logistics Industry}

The developed system aims to manage the stages of building a balanced scorecard for logistics companies. Fig. 2 illustrates the conceptual framework of the developed methodology by the author.

Stage 1: Define shared vision statement by involving all employees

Most of the logistics companies (especially single and medium-size enterprises) in Turkey have no shared and clear vision statement and a long-range planning. Global crisis and the changes in the global market affect them too much.

\section{BS-DSS suggests:}

- Interdisciplinary workshops are needed to define shared vision clearly. If possible, invite consultants and sector experts to the workshops and meetings. 
- The vision should have a future picture of 8 years later, at least.

Stage 2: Prepare a SWOT Analysis document related to vision statement and logistics industry.

BS-DSS suggests:

SWOT (Strength, Weaknesses, Opportunities and Threats) Analysis should focus the shared vision statement so that the strategies of company can be determined.

Sometimes a strength point may be also a weakness for the same company such as "to be a family firm". You may write it on the SWOT document both as a weakness and strength.

You may prepare a SWOT Matrix both for your company and your competitor(s) in the same table to benchmark and for other reasons.

\section{Figure 2. The conceptual framework of the developed decision support methodology}

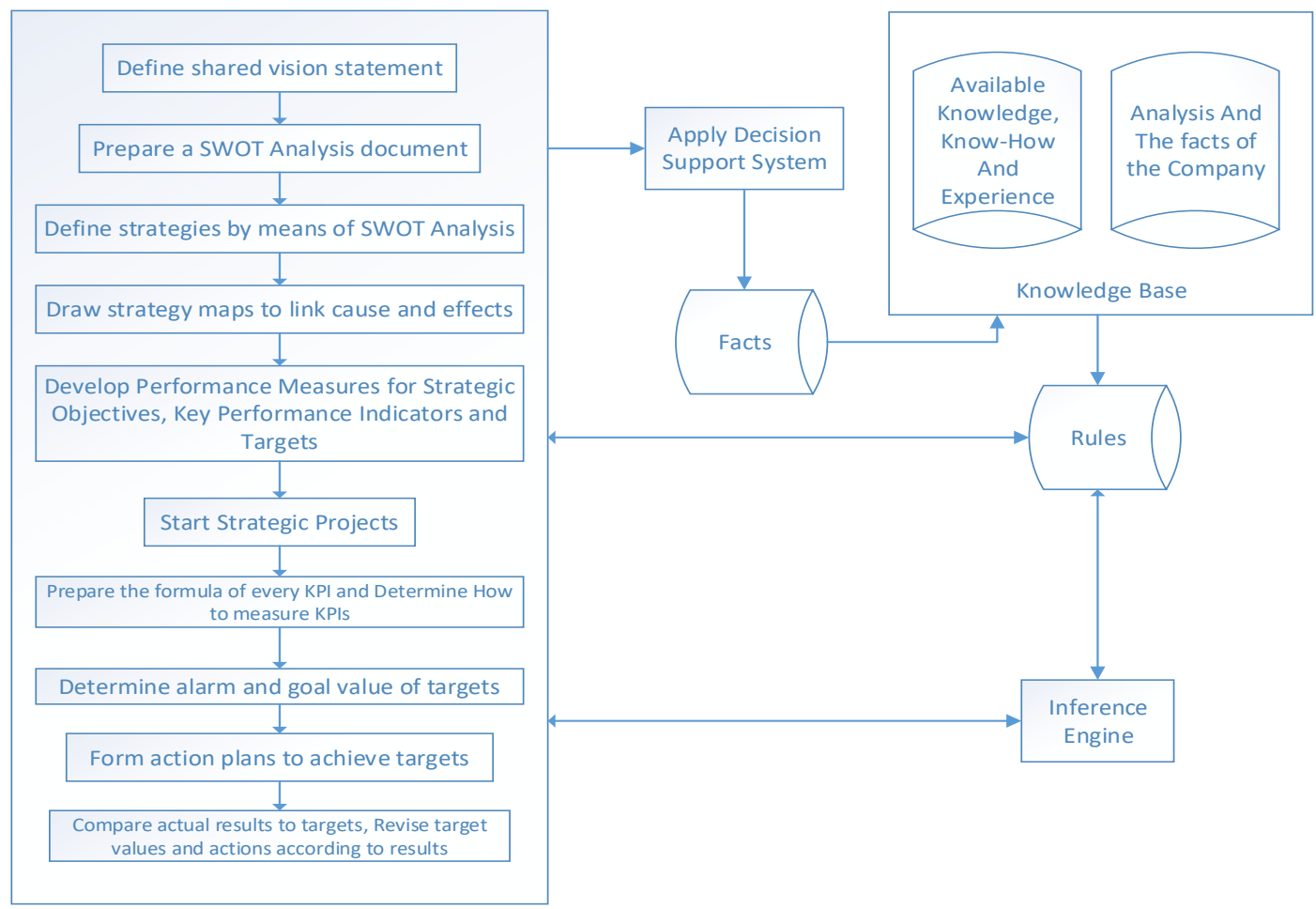

Stage 3: Define strategies by means of SWOT Analysis

BS-DSS suggests:

Consider future trends and global economy and their effects in logistics industry to determine right strategies.

Consider related topics for your company as follows (if related):

EDI (Electronic Data Interchange)

Big Data

Food Safety, (If your company transports or stocks food products)

Country-of-Origin,

Packaging

Private Labeling

Quality Management Systems

Traceability 
B2B, B2C, B2B2B2C, and etc.

Prepare a strategy about innovation as a logistics firm, if possible in your business segment.

Define 4-6 strategies (the ways to achieve the shared vision) as default. If you select more than 6 strategies, it is difficult to focus on them. If you select less than 4 strategies, it is difficult to realize the shared vision.

Stage 4: Draw strategy maps to link causes and effects

Most people have little information about strategy maps.

Kaplan and Norton (2000) explain strategy maps as follows:

Strategy maps show the cause-and-effect links by which specific improvements create desired outcomes - for example, how faster process-cycle times and enhanced employee capabilities will increase retention of customers and thus increase a company's revenues.

From a larger perspective, strategy maps show how an organization will convert its initiatives and resources - including intangible assets such as corporate culture and employee knowledge - into tangible outcomes.

Why Strategy Maps?

In the industrial age, companies created value by transforming raw materials into finished products. The economy was primarily based on tangible assets - inventory, land, factories, and equipment - and an organization could describe and document its business strategy by using financial tools such as general ledgers, income statements, and balance sheets.

In the information age, businesses must increasingly create and deploy intangible assets-for instance, customer relationships; employee skills and knowledge; information technologies; and a corporate culture that encourages innovation, problem solving, and general organizational improvements.

Even though intangible assets have become major sources of competitive advantage, no tools existed to describe them and the value they can create. The main difficulty is that the value of intangible assets depends on their organizational context and a company's strategy. For example, a growth-oriented sales strategy might require knowledge about customers, additional training for salespeople, new databases and information systems, a different organizational structure, and an incentive-based compensation program. Investing in just one of those items - or in a few of them but not all — would cause the strategy to fail. The value of an intangible asset such as a customer database cannot be considered separately from the organizational processes that will transform it and other assets - both intangible and tangible - into customer and financial outcomes. The value does not reside in any individual intangible asset. It arises from the entire set of assets and the strategy that links them together. (Kaplan and Norton, 2000)

BS-DSS suggests:

Select your KPIs from strategy maps so that you can deploy your objectives easily.

You may use a system dynamics-based simulation for better understanding of strategy maps. Capelo and Dias (2009) develop a theoretical model that explains the effectiveness of the balanced scorecard approach by means of a system dynamics and feedback learning perspective. It was concluded that a strategy map review positively influences mental model similarity, and mental model similarity positively influences performance.

See (Sterman 2000) for validation tests.

Derive KPIs and dashboards as much as from your ERP system to get results faster.

Stage 5: Develop Performance Measures for Strategic Objectives, Key Performance Indicators and Targets

BS-DSS suggests:

Determine balanced KPIs. It means not only financial KPIs, but also customer perspective, internal business processes perspective and learning \& growth perspective.

Let KPIs be S.M.A.R.T. ; 
Specific - target a specific area for improvement.

Measurable - quantify or at least suggest an indicator of progress.

Assignable - specify who will do it. Or Achievable.

Realistic - state what results can realistically be achieved, given available resources.

Time-related - specify when the result(s) can be achieved.

Define approximately 15 KPIs at company level.

Use necessary simulation techniques to understand the nature of important processes and their KPIs.

Stage 6: Start Strategic Projects

BS-DSS suggests:

Use Project Management tools and software to get satisfied results.

Stage 7: Prepare the formula of every KPI and Determine How to measure KPIs

BS-DSS suggests:

Get KPIs from ERP system as much as possible, then you will have results automatically.

Form important and value-added KPIs.

For example, a conventional "in-time delivery" KPI is formulated as follows:

Percentage of in-time-delivery $=100 *$ in-time-deliveries $/$ total deliveries.

If the quantities of delivered products are different,

We may use the formula of KPI as follows:

Rate of in time delivery $=100 *$ (quantities of in-time-deliveries / quantities of total deliveries).

Stage 8: Determine alarm and goal value of targets

BS-DSS suggests:

Assign last period's value as standard alarm value.

Assign 75 percent of goal value for project type targets. Because the deviation value of the targets is big for project type targets.

Stage 9: Form action plans to achieve targets

BS-DSS suggests:

Use P-D-C-A Kaizen (Continuous Improvement) methodology of Total Quality Management philosophy for Stage 9 and 10.

Stage 10: Compare actual results to targets, Revise target values and actions according to results.

BS-DSS suggests:

Go to the necessary stages according to your needs and manage your system.

\section{Industrial Case Study}

Logistics industry is one of the most important sectors for employment all over the world. Turkey's advantageous geographical location that stretches from Asia to Europe and Russia to Africa, allows it to be a hub for over USD 2 trillion freight carried in the region.

-According to Logistics Association in Turkey (LODER), Turkey's current logistics industry size is estimated to be USD 80-100 billion and is forecasted to reach USD 108-140 billion by 2017 .

-A strong and diversified economy will contribute to the expansion of the logistics industry. Since many industries support or rely on the logistics industry, their growth would indirectly stimulate the growth in logistics.

- Global logistics players are keen to invest in Turkey because of the growth potential within the Turkish economy and its proximity to Europe and Asia. Turkey has already attracted major global players. 
Turkey is building logistics centers/villages that will serve to lower the costs of transportation by offering various different modes of transportation within these centers/villages. It is estimated that by 2023 , total freight carried in the centers/villages will reach a total of USD 500 billion. [www.invest.gov.tr/enUS/infocenter/publications/Documents/TRANSPORTATION-LOGISTICS-INDUSTRY.pdf]

Turkey has a population of 76 million people and is growing with rising income levels. This makes Turkey one of the largest markets in its region, and the changing consumer habits of the younger generation boost domestic consumption.

Organizations are continuously looking for new ways to improve their performance and stay competitive in their markets.

Some logistics companies are visited and their processes are studied carefully. The logistics firms visited are Hedef Logistics, Imser Logistics, TTS Logistics. Two software house (Select: http://www.selectyazilim.com and Kesit, www.kesit.info ), expert about logistics software are visited and analyzed their software.

NMT logistics (http://nmtcapehorn.com.tr) was chosen to apply this study because of top management's commitment.

Stage 1: Define shared vision statement by involving all employees

NMT organized a vacation and meeting in a holiday village and all employees are participated. They prepared a clear vision statement together. The vision was determined by using a Balanced Scorecard project. A management consultant managed the Balanced Scorecard project and the top management supported this strategic management application. The vision, mission, strategies, perspectives and Key Performance Indicators are determined at the meetings by participating managers from all departments including top management.

NMT's shared vision statement is "to become the best company in south east Europe, and Middle East region."

Stage 2: Prepare a SWOT Analysis document related to vision statement and logistics industry.

NMT prepared a SWOT Analysis document related vision statement about the strengths, weaknesses, opportunities and threats of the company to clarify important strategy fields.

Stage 3: Define strategies by means of SWOT Analysis:

After a SWOT Analysis (Strengths, Weaknesses, Opportunities, and Threats), strategies are determined:

Decreasing costs by using six sigma projects for TQM and excellence.

Increasing the image by using and developing innovative service applications.

Using new technologies efficiently.

Sustaining the loyalty of the customers and the personnel as a part of TQM philosophy.

Since NMT is an SME, the management of NMT decided to define just 4 strategies to focus.

Stage 4: Draw strategy maps to link causes and effects

NMT prepared a strategy map for the strategy "Decreasing costs by using six sigma projects".

Stage 5: Develop Performance Measures for Strategic Objectives, Key Performance Indicators and Targets

NMT will decide to define the numbers of SMART KPIs at company level after system dynamics simulation to understand strategy maps.

NMT will use necessary simulation techniques to understand the nature of important processes and their KPIs.

Stage 6: Start Strategic Projects

NMT decided to start a Six Sigma Project supported by a six sigma consultant and the author of this paper. The first project is to shorten customer proposals and they decided to use simulation technique and 
Minitab statistics software for analyzing customer orders and proposals. The six sigma project increases the level of operational excellence.

Stages 7, 8, 9, and 10 will be analyzed according to the earlier stages' outputs.

NMT signed a contract to add balanced scorecard module with their ERP software company to customize the software.

\section{Managerial Implications and discussion}

The information how to apply a balanced scorecard methodology is vague and distributed in the literature and industry. Besides, the implementation of balanced scorecard in logistics is not well defined from vision into the action. Some existing papers focus only on earlier stages of balanced scorecard. This study helps managers to integrated implementation of balanced scorecard by defining 10 stages originally step by step. It has also expert knowledge for every stage to support managers. A lot of companies define approximately $100 \mathrm{KPIs}$ or more, while the approach recommends $15 \mathrm{KPIs}$ at company level according to expert knowledge by Norton and Kaplan. Therefore, this approach prevents the management from the problem of too much KPI defining, applying, measuring, controlling, and etc. Similarly, the approach suggests alarm value as default value (for example: "Select last period's value as default one".), target values to the managers. Another example is the number of strategies: Too many strategies yield the problem of focusing, whereas fewer strategies make it difficult to achieve the firm's shared vision.

How to form strategy maps and obtain KPIs are explained.

The necessary expert knowledge derived from related literature, industry experts and the writer's own experience, can be used by the managers.

\section{CONCLUSION}

In this study, the problem of the effective implementation of balanced scorecard has been analyzed by using decision support system approach and applied in logistics sector. A new decision support framework including 10 stages of balanced scorecard is developed originally:

Stage 1: Define shared vision statement by involving all employees

Stage 2: Prepare a SWOT Analysis document related to vision statement and logistics industry.

Stage 3: Define strategies by means of SWOT Analysis

Stage 4: Draw strategy maps to link cause and effects

Stage 5: Develop Performance Measures for Strategic Objectives, Key Performance Indicators and Targets

Stage 6: Start Strategic Projects

Stage 7: Prepare the formula of every KPI and Determine How to measure KPIs

Stage 8: Determine alarm and goal value of targets

Stage 9: Form action plans to achieve targets

Stage 10: Compare actual results to targets, Revise target values and actions according to results.

The developed decision support system framework has recommendations for every stage of balanced scorecard. Some logistics firms and ERP software houses are visited to obtain their knowledge, experiences. The necessary expert knowledge is derived from related literature, industry experts and the writer's own experience.

Balanced scorecard systems have a vital role for organizations to realize from their vision and strategies into the action.

This study shows that the developed new decision support system framework helps managers to apply balanced scorecard and also with TQM, Business Excellence, effectively. In this study, the focused strategy is "decreasing costs by using six sigma projects for TQM and excellence". The six sigma project also increases the level of operational excellence. Every strategy including typical strategies such as "merging", "innovation" and etc. can be used in this approach.

Strategic planners can use the methodology when attempting to identify strategic issues. 
The presented methodology is flexible and can be used for other sectors with some sector specific characteristics changes. The lessons from this logistics firm case or other applications can be added into the knowledgebase of the decision support system. Some machine learning tools and applications of system dynamics (for strategy maps) and other simulation techniques (for KPIs, and customer relations, and etc.) can also be studied as a further study.

The framework can also be used both other service industries and manufacturing companies, as another further research area. 


\section{REFERENCES}

Asan, Ş.S, \& Tanyaş, M. (2007), Integrating Hoshin Kanri and the balanced scorecard for strategic management: The case of higher education. Total Quality Management and Business Excellence, 18(9), 999-1014.

Capelo, C, Dias, J.F., (2009), “A system dynamics-based simulation experiment for testing mental model and performance effects of using the balanced scorecard", System Dynamics Review Vol. 25, No. 1, 134

Cebeci, U. (2009), Fuzzy AHP-based decision support system for selecting ERP systems in textile industry by using balanced scorecard, Expert Systems with Applications, 36, 8900-8909

Chang, W. C., Tung, Y. C., Huang, C. H., \& Yang, M. C. (2008). Performance improvement after implementing the Balanced Scorecard: A large hospital's experience in Taiwan. Total Quality Management and Business Excellence, 19(11), 1143-1154.

Esteves, J. (2009) "A benefits realisation road-map framework for ERP usage in small and medium-sized enterprises", Journal of Enterprise Information Management, Vol. 22, No: 1/2, pp. 25-35.

Federici, T., (2009) "Factors influencing ERP outcomes in SMEs: a post introduction assessment", Journal of Enterprise Information Management, Vol. 22, No: 1, pp. 81-98.

Ford, F. N. \&. Rager, J. (1995) "Expert system support in the textile industry: End product production planning decisions", Expert Systems with Applications, Vol. 9, pp 237-246.

Garengo, P., \& Biazzo, S. (2012). Unveiling strategy in SMEs through balanced scorecard implementation: A circular methodology. Total Quality Management \& Business Excellence, 23(1), 79102.

Gorry, G.A. and Scott Morton, M.S., "A framework for management information systems", Sloan Management Review, Fall, 1971, pp. 55-70.

Gunasekaran, A. and Kobu, B. (2007), "Performance measures and metrics in logistics and supply chain management: a review of recent literature (1995-2004) for research and applications", International Journal of Production Research, Vol. 45 No. 12, pp. 2819-40.

H.C. Huang, (2009), Designing a knowledge-based system for strategic planning: a balanced scorecard perspective, Expert Systems with Applications 36 (1) 209-218.

Hussain, T., Wardman R. H. and Shamey R. (2005) "A knowledge-based expert system for dyeing of cotton. Part 1: Design and development”, Coloration Technology, Vol. 121, pp. 53-58

Kalkan, A., Bozkurt, O.C., OZTOP, S., Siseci, Cesmeli, M. (2015) "Strategic management approach in the metropolitan municipalities in Turkey: An Analysis On The Statements Of Mission, Vision And Core Values", Journal of Global Strategic Management, V. 9, N. 1, 65-74

Kaplan, R. S., \& Norton, D. P. (1992). The balanced scorecard-measures that drive performance. Harvard Business Review, 70(1), 71-79.

Kaplan, R. S., \& Norton, D. P. (1996). The balanced scorecard: Translating strategy into action. Boston, MA: Harvard Business School Press.

Kaplan, R.S., Norton, D.P. (2000) "Having Trouble with Your Strategy? Then Map It”, Harvard Business Review, Sept-Oct, pp. 167-176

Laudon, K. C. \&. L. J. P., "Essential of management information systems”, 2002.

McAdam, R., \& O'Neill, E. (1999). Taking a critical perspective to the European Business Excellence Model using a balanced scorecard approach: a case study in the service sector. Managing Service Quality: An International Journal, 9(3), 191-197.

Metaxiotis, K. (2004) "RECOT: An expert system for the reduction of environmental cost in the textile industry", Information Management \& Computer Security, Vol. 12, pp. 218 - 227 
Pimentel, L., \& Major, M. J. (2014). Quality management and a balanced scorecard as supporting frameworks for a new management model and organisational change. Total Quality Management \& Business Excellence,25(7-8), 763-775.

Rajesh, R., Pugazhendhi, S., Ganesh, K., Ducq, Y., \& Koh, S. L. (2012). Generic balanced scorecard framework for third party logistics service provider. International Journal of Production Economics, 140(1), 269-282.

Ritchie-Dunham J, Morrice D, Anderson E, Dyer J. 2007. “A simulation exercise to illustrate the impact of an enterprise system on a service supply chain", INFORMS Transactions on Education 7(3), pp. 201222.

Sarma, V. (1994), "Decision-making in complex-systems", System Practice 7. (4) (1994), pp. 399-407.

Singh, S., Olugu, E. U., Musa, S. N., \& Mahat, A. B. (2018). Fuzzy-based sustainability evaluation method for manufacturing SMEs using balanced scorecard framework. Journal of Intelligent Manufacturing, 29(1), 1-18.

Sterman, J. D. 2000. Business Dynamics: Systems Thinking and Modeling for a Complex World. Irwin McGraw-Hill, Boston.

Xia, D., Yu, Q., Gao, Q., \& Cheng, G. (2017). Sustainable technology selection decision-making model for enterprise in supply chain: Based on a modified strategic balanced scorecard. Journal of Cleaner Production, 141, 1337-1348.

Wu, S. I., \& Hung, J. M. (2007). The performance measurement of cause-related marketing by balance scorecard. Total Quality Management \& Business Excellence, 18(7), 771-791. 